\title{
AVANÇOS DA MUSICOTERAPIA EM PACIENTES COM SÍNDROME DE DOWN
}

\author{
Eduarda Rehder Ferreira Figueiredo Nardi', Marco Antônio Forastieri Mansano² \\ Sandra Cristina Catelan - Mainardes ${ }^{3}$
${ }^{1}$ Acadêmica do Curso de Medicina, Centro Universitário de Maringá - PIC/UNICESUMAR. eduarda rehder@hotmail.com 2 Acadêmico do Curso de Medicina, Centro Universitário de Maringá - UNICESUMAR. mafmansano@hotmail.com 3. Orientadora, Mestre, Docente na área da Saúde, Centro Universitário de Maringá - UNICESUMAR. sandra.mainardes@unicesumar.edu.br

RESUMO

A pesquisa sobre "AVANÇOS DA MUSICOTERAPIA EM PACIENTES COM SÍNDROME DE DOWN" tem como objetivo avaliar os resultados da aplicação da Musicoterapia em alunos portadores da Síndrome de Down (SD) da APAE-Maringá-PR. A pesquisa se baseará na seleção de um grupo de alunos com SD, com idade máxima até 21 anos, que possuam o maior número de características em comum, para que não ocorram distorções nos resultados, por exemplo, a associação com outras condições que o aluno possa apresentar além da alteração genética, exemplificada por influências no uso de medicamentos e outras comorbidades associadas. A partir do grupo selecionado pelos pesquisadores, será utilizado músicas, que se acredita possuir um maior efeito no desenvolvimento dos pacientes e, a partir daí, serão analisados o resultado da música durante as sessões, o reflexo que vem apresentando no comportamento diário do mesmo e se houveram evoluções presentes nos relatos apresentados previamente, por meio de entrevistas com os pais dos alunos e equipe pedagógica escolar.

PALAVRAS-CHAVE: Desenvolvimento cognitivo-motor e linguagem; Musicoterapia; Síndrome de Down.

\section{INTRODUÇÃO}

A Síndrome de Down (SD), caracterizada pela alteração genética que resulta em uma terceira cópia do cromossomo 21 (trissomia), é a ocorrência genética mais comum no Brasil, de acordo com a estimativa do Instituto Brasileiro de Geografia e Estatística (IBGE, 2010), aproximadamente 300 mil brasileiros são portadores desta condição. A SD pode ser caracterizada sob vários aspectos, dentre eles, orgânicos, cognitivos e motores, entre outros.

A SD tem como característica o atraso no desenvolvimento intelectual, de maneira que, o portador é capaz de desenvolver as mesmas habilidades cognitivas e motoras comparado a uma criança de desenvolvimento típico, contudo, terá o desenvolvimento tardio das mesmas. (BONOMO \& ROSSETI, 2010). Buckley e Bird (1994) caracterizaram o desenvolvimento cognitivo da criança com SD de acordo com: o atraso no desenvolvimento linguístico expressivo e receptivo, decorrente de sua dificuldade na percepção auditiva; dificuldade da articulação da escrita advinda da hipotonia corporal; atraso no desenvolvimento oral devido a problemas com a memória operacional, caracterizada pela capacidade de memória auditiva de curto-prazo mais breve, o que dificulta a aquisição e consolidação da linguagem.

O desenvolvimento motor das crianças com SD são parecidos com a de crianças normais, apenas mais lento e gradativo, apresentando atrasos de aquisições de marcos motores considerados básicos, como sorrir (6 meses), sentar-se sozinho ( 9 meses), ficar em pé com apoio (15 meses), e andar (19 meses), quando comparadas a crianças com 
desenvolvimento típico ( 3 meses, 7 meses, 8 meses e 12 meses, respectivamente). (ARAKI \& BAGAGI, 2014).Dessa forma, para que possa ocorrer um melhor desenvolvimento cognitivo-motor das crianças com SD, são necessários estímulos possam transformar a rotina de atividades estimuladora em prazer, por meio de estimulações multissensoriais, por exemplo, aguçando o olfato, o paladar, a visão, e, principalmente, a audição, usando a música ao seu favor, já que, apesar de sua dificuldade na percepção auditiva, são extremamente musicais.

\begin{abstract}
A Musicoterapia é a utilização da música e/ou seus elementos (som, ritmo, melodia e harmonia) por um musicoterapeuta qualificado, com um cliente ou grupo, num processo para facilitar e promover a comunicação, relação, aprendizagem, mobilização, expressão, organização e outros objetivos terapêuticos relevantes, no sentido de alcançar necessidades físicas, emocionais, mentais, sociais e cognitivas. A Musicoterapia objetiva desenvolver potenciais e/ou restabelecer funções do indivíduo para que ele/ela possa alcançar uma melhor integração intra e/ou interpessoal e, consequentemente, uma melhor qualidade de vida, pela prevenção, reabilitação ou tratamento - Federação Mundial de Musicoterapia (World Federation of Music Therapy) (WFMT, 1996).
\end{abstract}

A partir desta definição publicada na Revista Brasileira de Musicoterapia, a música é apontada como uma ferramenta alternativa de força associativa que visa a qualidade de vida do paciente, atuando como estratégia facilitadora de dimensões mentais e psicológicas, sociais e espirituais, que produzem efeitos de comunicação, integração e recuperação do cliente. (SOUSA, 2010). Dessa forma, a musicoterapia é desenvolvida por meio da utilização da música e de seus recursos sonoros, onde a dinâmica será estruturada pelo musicoterapeuta em conjunto com o paciente e/ou grupo, com o objetivo da promoção humanizada de comunicação, aprendizagem, autonomia, organização (mental, social e cognitiva), além de contribuir para o alívio da dor e melhora das condições psicológicas do indivíduo. (BARCELOS, et al; 2018)

$\mathrm{Na}$ medicina, a musicoterapia contribui para o desenvolvimento do ser humano como um todo e de maneira única, por utilizar de elementos abstratos que são percebidos pelo indivíduo com o passar do tempo, formando o complexo som-ser humano-som por meio de seus elementos estruturais (altura, timbre, intensidade, melodia, harmonia, ritmo), proporcionando a abertura do paciente, tanto na comunicação e interação social. (GODOY \& FAUSTINO, 2016). A musicista Leão (2001), afirma que o indivíduo ao ser inserido na música, tem o favorecimento do desenvolvimento motor e de propriocepção, como o equilíbrio dinâmico e estático, coordenação de mãos e de olhos, habilidades de escuta promovendo o pensamento linear e planejamento de ações.

Por fim, pouco se consta na literatura acerca dos benefícios da musicoterapia na SD, contudo, os estudos já realizados sobre o assunto trazem como resultado, que programas de intervenções precoces utilizando a música como terapia alternativa para os portadores da síndrome, alcançaram sucesso no avanço dos domínios cognitivos da linguagem verbal e não verbal, da leitura, demonstração de emoções, além da melhoria nos domínios motores, iniciativas de experiências de dança, canto, simulação de movimentos de toque dos instrumentos musicais e expressões de emoção por meio de gestos. (PIENAAR, 2012). Assim, com a aplicabilidade deste estudo, poderemos constatar as múltiplas evoluções motoras, cognitivas e sociais, que são esperadas por meio da metodologia a ser utilizada.

\title{
2 MATERIAIS E MÉTODOS
}


A metodologia da pesquisa consistirá em realizar entrevistas e acompanhamento da evolução dos alunos da APAE de Maringá. Visa conhecer o ambiente onde irá ser desenvolvido o projeto, e analisar o cadastro dos pacientes portadores de Síndrome de Down. Identificar quais alunos possuem doenças associadas; medicamentos utilizados; tipos musicais que apresentam maior interesse e afinidade; se os alunos fazem outras terapias associadas. Após se ter conhecimento da condição de cada aluno, será realizado um processo de seleção dos mesmos, como forma de restringir o grupo apenas a alunos que não possuam outras comorbidades ou doenças associadas, e o não consumo de medicamentos que possam alterar os resultados da pesquisa quando comparados aos demais, para assim aplicar a pesquisa em um grupo mais homogêneo possível. Além disso, o grupo irá consistir em alunos de diferentes idades, com no máximo 21 anos, para que possam ser avaliados os resultados nas diferentes etapas do desenvolvimento dos indivíduos portadores de Síndrome de Down. A seleção das músicas que serão usadas como objetivo de terapia ocorrerá sob o auxílio do Musicoterapeuta, e terá como ponto de partida pesquisas dentre os estilos e ritmos musicais que o grupo possui predominantemente maior afinidade, aptidão, e histórico de respostas positivas, onde se acredita poder alcançar um maior resultado para os alunos portadores de Síndrome de Down. As sessões de musicoterapia acontecerão uma vez por semana, no período de 30 minutos, por 08 semanas, na sala de Musicoterapia. Serão aplicadas 5 músicas selecionadas previamente aos alunos em cada sessão, sendo 2 dessas músicas fixas para todas as sessões. Após esta delimitação a equipe de pesquisa planeja uma entrevista estruturada e semiaberta, com oito perguntas, sendo duas perguntas fechadas e seis abertas para os pais e oito perguntas abertas para a musicoterapeuta. $O$ instrumento para coleta de dados será aplicado mediante a aprovação dos participantes no projeto, que assinarão o Termo de Consentimento Livre e Esclarecido (TCLE). A coleta dos dados das entrevistas será feita através de gravação de áudio, para análises posteriores. As análises serão realizadas na forma de Análise de Conteúdo de modelo aberto e buscam abranger os âmbitos qualitativo e quantitativo, uma vez que as entrevistas possuíam perguntas abertas e fechadas. As perguntas buscarão saber o que os pais notaram de diferenças em seus filhos depois que passaram pela intervenção da Musicoterapia, questionando desde a quantidade de tempo pelo qual a criança passou pelo atendimento até qual tipo de habilidade foi predominantemente adquirida pelo participante, além de percepção de mudanças comportamentais, de relacionamento e de humor, como também avaliações relacionadas a parte motora do participante. Para o musicoterapeuta, as perguntas buscam esclarecer mais sobre a importância da música no desenvolvimento dos participantes. Desse modo, as perguntas buscarão aprofundar no tema, encontrar respostas para o problema de pesquisa e estabelecer padrões de respostas que poderão ser analisadas posteriormente, visando encontrar respostas que levantem hipóteses sobre os benefícios deste tipo de terapia. Serão observados e anotados individualmente os resultados gerados, para que se possa avaliá-los e concluir se estão dentro do esperado e qual a evolução alcançada no transcorrer da aplicabilidade do método.

\section{$3 \quad$ RESULTADOS E DISCUSSÕES}

A pesquisa se encontra em andamento.

\section{REFERÊNCIAS}


ARAKI, I.P.M.; BAGAGI, P.S. Síndrome de Down e o seu Desenvolvimento Motor. Rev. Cient. Eletro. de Ped. 2014; Ano XIV - Número. 23, 2014.

BARCELOS, V.M.; TEIXEIRA, E.R.; RIBEIRO, A.B.N. et al. A Musicoterapia em Pacientes Portadores de Transtorno Mental. Rev. Enferm. UFPE online., Recife, 12(4):1054-9, abr., 2018.

BONOMO, LMM; ROSSETTI, CB. Aspectos percepto-motores e cognitivos do desenvolvimento de crianças com Síndrome de Down. Rev. Bras. Cresc. e Desenv. Hum. 2010; 20(3) 723-734.

BUCKLEY, S.J. e BIRD, G. Meeting the educational needs of children with Down syndrome. Portsmouth: Sarah Duffen Centre/University of Portsmouth, 1994.

GODOY, H.P.; FAUSTINO, R. A Musicoterapia como Instrumento na Intervenção Psicopedagógica com Crianças Portadoras de Autismo. Uníttalo em Pesquisa. São Paulo SP, vol. 6, no. 3., p. 117-135, jul/2016.

Instituto Brasileiro de Geografia e Estatística 2010. Censo Demográfico 2010. Rio de Janeiro: IBGE, 2010.

LEÃO, E.. Por que estudar música? Revista da Adufg (Seção Sindical da ANDES), n. 06, p. 34-42, jan/abr 2001.

MOVIMENTO DOWN. Portal de rede de informações para pais e pessoas com Síndrome de Down. Rio de Janeiro, 2012. < Disponível em: http://www.movimentodown.org.br/.

PIENAAR, D. Music Therapy for Children with Down Syndrome: Perceptions of Caregivers in a Special School Setting. University of Auckland, 2012.

Revista Brasileira de Musicoterapia - UBAM, Ano 1 - Número 2, 1996 < Disponível em: http://www.revistademusicoterapia.mus.br/1996/08/08/ano-i-numero-2-1996/>

SOUSA, M.E.M. A Musicoterapia na Socialização das Crianças com Perturbação do Espectro do Autismo. Porto, 2010. 